\title{
Nurses' Compliance with Infection Prevention and Control Practices at General Surgical Units
}

\author{
Elijah Kipkorir Koros, Staff Nurse \\ Moi Teaching and Referral Hospital, Eldoret, Kenya
}

Sanaa Mohamed Alaa Eldin, Professor

Medical Surgical Nursing, Faculty of Nursing, Alexandria University

\author{
Haneya Mohamed El-Banna, Professor \\ Medical Surgical Nursing, Faculty of Nursing, Alexandria University
}

\author{
Lilian Adhiambo Omondi, Lecturer \\ Medical Surgical Nursing, School of Nursing, University of Nairobi, Kenya
}

\begin{abstract}
Hospital-acquired infections results due to lapsed compliance with Infection prevention and control practices in health care set ups. Nurses provide direct care to the patients while performing varied clinical procedures; therefore, they are pivotal in implementation of infection prevention and control practices. Objective: Assess the nurses' compliance with infection prevention and control practices in surgical units. Setting: The study was conducted at the Moi Teaching and Referral Hospital Surgical wards Eldoret, Kenya. Subjects: Data was collected from 100 randomly selected surgical nurses. Tools: Two tools were utilized; interviewer-administered questionnaire and structured observational checklist. Results: Sixty nine percent of the nurses were compliant with recommended hand hygiene practices; $99 \%$ of the nurses used gloves but fewer used other personal protective equipment like goggles (25\%) and gowns (37\%). Seventy percent of were compliant with safe injection practices. In overall, $85.6 \%$ of studied nurses reported to be compliant while $80 \%$ of them were observed to be compliant. Conclusion: Most of the studied nurses complied with the recommended infection prevention and control practices but compliance varied across different domains of practice indications. Recommendations: The hospital should develop infection prevention and control guidelines specific to surgical units.
\end{abstract}

Keywords: Infection prevention and control; Nurses compliance.

\section{Introduction}

Infection control is an essential element within the confines of a health-care delivery system concerned with preventing healthcare-associated infections (HCAIs) ${ }^{(1)}$. Infection prevention and control utilizes systematic practices, measures and protocols to mitigate the threats posed by health care associated infections $(\mathrm{HCAIs})^{(2,3)}$. These measures are aimed at creating a safe healthcare environment through the implementation of practices that lessen the risk of transmission of infectious agents $^{(2)}$.

Infections in health care settings is a global problem representing one of the key causes of morbidity and mortality associated with hospitalization ${ }^{(4)}$. World Health Organization (WHO) estimated that $7-10 \%$ of hospitalized patients at any given time will acquire at least one health careassociated infection leading to significant mortality $(5-10 \%)$ with financial losses for health systems ${ }^{(5,6)}$. Fortunately, Bagheri et al. (2014) stated that, HCAIs are potentially preventable adverse event rather than an erratic complication with effective infection prevention and control (IPC) practices adherence $^{(4)}$.

Health care associated infections have continued to plague users of health care settings since their inception as institutions for healing the sick despite major advances in health care technologies and scientific discoveries. Consequently, IPC has since 
become a constant and fundamental safety issue in nearly all health facilities in developed countries ${ }^{(6)}$. Most patient safety programs have anchored universal safe IPC practices in the clinical settings to mitigate the dangers posed by such HCAIs ${ }^{(2)}$.

Reports of HCAIs rates in most African countries are inadequate; some literature on incidence of HCAI outbreaks and hospital-wide prevalence surveys revealed rates ranging between $2.5 \%$ and $14.8 \%^{(7)}$, in Egypt the documented prevalence is $16 \%$ and as high as $26 \%$ in intensive care units and in India $6-18 \%{ }^{(8)}$. Some systematic reviews indicate that surgical sites infection (SSIs) averages $5.7 \%$ to $30 \%$ in African countries; in Tanzania 19\%, Uganda $10 \%$, Benin $22.3 \%$ and in Kenya $19 \%{ }^{(9)}$.

In Kenya there is very scanty information on studies regarding HCAIs and more so SSIs. Therefore the actual burden of HCAIs is yet to be accurately quantified; available studies estimated its prevalence at about $10-25 \%$ of total hospital admissions in government facilities ${ }^{(10,11)}$. These illustrate well the pressing need to identify and execute viable and sustainable approaches to strengthen HCAI prevention, surveillance, and control not only in Africa, but more specifically in Kenya.

Center for diseases prevention and control (CDC) recommends isolation precautions for effective prevention of HCAIs in hospitals. These precautions are in two tiers: standard precautions (SP) and transmission based precautions (TBP). Standard includes a cluster of infection prevention practices that apply to every patient, in spite of suspected or confirmed infection status, in every setting in which healthcare is delivered ${ }^{(12)}$.

The main domains of SP include; hand hygiene; use of personal protective equipments (gloves, gown, mask, eye protection, or face shield) depending on the anticipated exposure; and safe injection practices. Also, care of equipment or items in the patient environment and waste management. Implementation of these SP practices constitutes the primary IPC strategy for the prevention of healthcareassociated infections ${ }^{(10,13)}$. Documented evidence has shown that the incidence of postoperative infections can be reduced by $20 \%$ to $34 \%$ through adoption of "safe and sound" patient care practices ${ }^{(14)}$. Systematic reviews of evidence points to non compliance to these IPC practices and procedures by health care workers as attributable to increased risk for HCAIs ${ }^{(15)}$.

In Kenya, a study done by Storr et al. (2017) estimated health care workers' IPC practices compliance rate in primary health care facilities at $31 \%{ }^{(6)}$. In a self reported study in another Kenyan hospital the compliance was $61 \%{ }^{(16)}$. This is despite the fact that hospitals are the epicenter of HCAIs; where compliance with IPC practices must be adhered with strictest sense. Such findings reflect selective and suboptimal compliance by health professionals which exposes them to avoidable risks ${ }^{(17)}$.

Nurses form the bulk of the health care workers (HCWs) team and are in the frontline in health care delivery ${ }^{(18)}$. Routine nursing services and procedures are closely entwined with IPC practices owing to the close proximity and interaction nurses have with different patients with assorted infections. This makes nurses have an important role in breaking the chain of infection by strictly complying with IPC practice indications $^{(19)}$.

There has been little information on IPC practice compliance research in low and middle-income countries, and particularly in Kenya. There is no evidence at Moi Teaching and Referral Hospital (MTRH) as regards to the level of compliance to IPC practices by surgical wards nurses. This study therefore aimed to determine the level of compliance by nurses with IPC practices in MTRH. The results will present much needed evidence for planning, designing and implementation of infection prevention and control strategies, geared towards reinforcing sustainable and consistent IPC practices. The study results 
as well will provide basis for further research relating to impact of the resultant compliance level.

\section{Aim of the Study}

This study aimed to assess nurses' compliance with infection control practices in general surgical units at MTRH, EldoretKenya.

\section{Research Question:}

What is the nurses' compliance level to infection prevention and control practices in general surgical units at MTRH, EldoretKenya?

\section{Materials and Method}

\section{Materials}

Design: A descriptive research design was be utilized to carry out this study.

Setting: The study was conducted at the inpatient surgical units of Moi Teaching and Referral Hospital (MTRH), Eldoret, Kenya.

Subjects: Subjects of the study consisted of a random sample of 100 nurses working at the surgical units for at least the past six months who consented for the study. Epi info program V 7.0 was used to find the sample size.

Tools: Two tools were utilized in conducting this study for data collection:

Tool I: Surgical Nurses' Compliance with IPC Practices Questionnaire

This tool was developed by the researcher after extensive review of related and had it comprised of two parts as follows:

Part 1: Nurses Bio-socio-demographic Data: such as age, gender, education level, ranking, employment, hepatitis B vaccination status, years of work experience, history of sharps injury and attendance of courses relevant to the IPC practices as well as a serial code identifier of the questionnaire.
Part 2: Nurses' Self Reported Compliance with IPC Practices: Comprised statements relating to the assessment of nurses' frequency of compliance with IPC practices on a 3 point likert scale (Always, sometimes and never). The compliance practices included group of statements relating to: Hand hygiene, personal protective devices, safe injection practices, linen management, waste disposal and surgical dressing aseptic technique. Nurses' responses were scored on a 3 point likert scale ranging from "Always (score 2)", "sometimes (score 1)" and "never (score 0)". The total score for this part was calculated and converted into percentage scores. Subtotal and total percent scores of $\geq 75 \%$ denote compliance, while scores of $<75 \%$ implied noncompliance.

Tool II: Infection Prevention and Control Compliance Observation Checklist

This tool was used to record the nurses' observed compliance with IPC practices as they were performing nursing procedures. The checklist was linked to tool (I) by use of code identifier. It comprised of IPC practice items with expected compliance activities relating to: Hand hygiene, personal protective devices, safe injection practices, linen management, waste disposal and surgical dressing aseptic technique. A score of 1 was given for compliant and 0 for none compliant. The total score for this part was calculated and converted into percentage score. Subtotal and total percent scores of $\geq 75 \%$ (scores of $\geq 31.5$ ) denotes compliance, while scores of $<75 \%$ (scores of $<31.5$ ) implies noncompliance.

\section{Method}

- The study protocol was approved by Faculty of Nursing Alexandria University ethics committee and Moi University/Moi Teaching and Referral Hospital (MTRH) Institutional Research and Ethics Committee (IREC). Likewise, MTRH administrative authorities. 
- Tool (I) was developed and tool (II) was modified by the researcher based on extensive review of the relevant literature.

- Content validity of both tools was tested by a jury of 5 experts specialized in the field of medical surgical nursing in Alexandria university to test for tools clarity, completeness and comprehensiveness.

- Reliability of tool (1) was tested by using Cronbach's Alpha test. The tool was found to be internally reliable with Cronbach's Alpha coefficient of (0.806).

- Pilot study was carried out on 10 nurses (10\% of study sample) to test the feasibility, clarity and applicability of the study tools.

\section{- Data collection process:}

- Simple random sampling using proportionate allocation method to all surgical wards was used to obtain the total sample size of 100 surgical nurses.

- Randomly selected nurse participants were observed for 2-3 hours using concealed observations for opportunities during nursing care requiring application of IPC practices. The nurses' actual practices were recorded by the researcher using tool II. Individual nurses were only observed once for the specified IPC practice application.

- After finishing all the observations, the observed nurses were interviewed using tool (I) which had the same code identifier as tool (II) for between 30-45 minutes.

\section{Ethical considerations:}

- Informed written nurses' consent was obtained after explanation of the aim of the study.

- Nurses' were informed that their participation was voluntary, their privacy and right to withdraw from the study was respected.

- The anonymity, security and confidentiality of collected data were ascertained.

\section{Statistical Analysis}

- The raw data collected was coded and entered into statistical Package for social scientists (SPSS) version 20 software data sheet, data was then cleaned and verified using the primary source documents(tool I or II). Statistical analysis was performed using SPSS version 20 where descriptive statistics were generated for categorical and continuous variables.

- The association between quantified qualitative variables was assessed using Pearson's chi square test $\left(\mathbf{X}^{\mathbf{2}}\right)$. The exact tests were used as alternatives when: The overall total of the table was less than 20 , or the overall total was between 20 and 40 but with the smallest of the expected numbers in any of the cells being less than 5. The level of significance selected for this study was $\mathrm{p} \leq 0.05$.

- T-test was used for comparison between quantitative data in the same group $\mathrm{p} \leq 0.05$.

\section{Results}

Table (1) shows that a total of 100 nurses consented and participated in this study, slightly more than three quarters $(76.0 \%)$ were females and $24 \%$ were male. Almost two thirds of the nurses $(64 \%)$ had diploma in nursing; with $35 \%$ having bachelor's degree. Majority of the nurses (79\%) had been vaccinated against Hepatitis B, of those who were vaccinated only about two thirds $(65.8 \%)$ had received all the three doses recommended for protection.

Table (2a) illustrates that nearly a third $(63 \%)$ of the nurses acknowledged performing hand hygiene $(\mathrm{HH})$ "always", 
before contact with any patients but nearly half $(47 \%)$ reported to do so when in contact with different patients. The overall nurses' compliance in hand hygiene domain was $69 \%$. Most nurses $(99 \%)$ were compliant with IPC practice indications of gloves use with percent scores of $96.85 \pm 5.25$.

Table (2b) exhibits that $66 \%$ and $25 \%$ of the studied nurses acknowledged wearing a mask and protective eye patch/goggles respectively. When handling soiled linen, a large majority of the nurses (94\%) used gloves with $73 \%$ folding them with contamination to the inside.

Table (2c) the overall participants' "compliance" with safe injection practices domain was $70 \%$. The overall self reported compliance score for all the domains was $85.58 \pm 8.35$.

Table (3a) demonstrates that less than half $(49 \%)$ of the observed nurses performed hand hygiene before contact with any patients. When in contact with different patients, almost a third of the nurses $(35 \%)$ were compliant with the recommended hand hygiene practices. In relation to use of masks/goggles while performing procedures that might induce spraying of blood, body fluid, secretions and excretions; majority of nurses wore face masks (77\%), however very few wore protective eye patch/goggles $(14 \%)$ or protective suit/gowns $(38 \%)$. The overall compliance in this domain was $92 \%$.

Table (3b) illustrates that in linen management; most nurses $(94 \%)$ wore gloves before handling soiled linen. The table further exhibits that waste generation and disposal was in accordance with hospital policy in $80 \%$ of the observed cases, also most of the observed nurses discarded sharps (95\%) and infectious waste $(80 \%)$ into the designated receptacles. Also, it is evident from this table that the majority of the participants' during wound dressing; cleaned the trolley $(85 \%)$ and checked the integrity of the sterile pack $(65 \%)$. Nevertheless, less than half of them $(46 \%)$ checked the expiry date of the packs. Moreover, more than half of them maintained the sterility of the field. In total, the compliance in this domain was $55 \%$.

Table (4) exemplify that no association was found between studied nurses' selfreported compliance with IPC activities and their social demographic factors or work related characteristics.

Table (5) exhibits that in two domains: hand hygiene and use of personal protective equipments, the results demonstrates a significant difference $(p=0.001)$. This shows that in hand hygiene, nurses reports to perform $\mathrm{HH}$ practices more than they actually do under observations. Also in regards to PPE use, it implies nurses' reports to use PPEs than they actually under observation. The overall difference in self reported compliance and observed compliance was also significant $(\mathrm{p}=0.001)$.

\section{Discussion}

Patients admitted especially in surgical units are at increased risks of all types of HCAIs; it has been approximated that more than $10 \%$ of such patients admitted in most hospitals contract clinically significant HCAIs; $50 \%$ being SSIs ${ }^{(20)}$. Subsequently, there is a particular need for strict observation of IPC measures against cross infection when caring for patients undergoing treatment in surgical units ${ }^{(21)}$. Therefore all HCWs must apply IPC measures during their interactions with all patients at all the times to lessen the spread of HCAIs ${ }^{(2)}$. The main problem however, is non adherence with IPC measures by care givers when performing ward procedures ${ }^{(6)}$.

The demographics of this study agree in many aspects with those of many other studies done among nurses. In terms of gender, majority of the participants in this study were females; similar to that of Ganesh et al. (2016) ${ }^{(22)}$, Kamunge (2017) ${ }^{(23)}$ and Chisanga $(2017)^{(24)}$. Kenya nursing workforce report by Martha Rogers (2012) shows the same trend with less than a third of nursing workforce being male ${ }^{(25)}$. This reaffirms the notion that nursing is still predominantly female dominated profession $^{(26)}$. 
Concerning the level of education, majority of the nurses in this study had diploma in nursing. This was in agreement with other studies done by Moyo (2013) ${ }^{(27)}$ and Shurafi (2015) ${ }^{(28)}$ where majority of the nurses are diploma holders. Kamunge $(2013)^{(23)}$ study however, revealed that $70 \%$ of the nurses had bachelors degree in Nursing. In Kenya, majority of the nurses are holders of diploma certificates. Ministry of health in Kenya approximates that only $3 \%$ of the nurses have a degree in nursing ${ }^{(25)}$. This is not surprising though because most nursing training institutions in Kenya offer diploma level of education. Some studies have shown significant association between higher levels of education and higher knowledge as well as improved compliance with infection prevention and control practices ${ }^{(26)}$.

In this study, it is notable that less than a quarter of the nurses reported to having attended IPC training six months prior to this study. Tirivanhu et al. $(2014)^{(29)}$ while exploring barriers to IPC practice among nurses in a Zimbabwean hospital indicated that more than two thirds of nurses had not attended any infection prevention and control workshops. This may be attributed to high workload, fewer years of experience and poor arrangements of workshops. Ongoing trainings on IPC practices is regarded as one of the best strategies to improve knowledge and refine practice skills necessary for compliance with IPC measures ${ }^{(30)}$.

Although the variables of age, gender, training and level of education were theoretically validated variables in this study, they were found to be nonsignificantly associated with IPC compliance. This could be due to the fact that the population which was sampled was homogenous in regards to most these variables. The vast majority of participants were female, aged below forty, diploma holders with a few trained in IPC practices. Most training courses were of short duration.
Hepatitis B virus infection continues to pose a major risk to nurses despite its vaccines having proved safe and protective against it. Vaccination against $\mathrm{HBV}$ is highly recommended for all HCWs and especially nurses ${ }^{(31)}$. In this study more than three quarters of the nurses had been vaccinated against $\mathrm{HBV}$, however only a third received all the three doses recommended for protection. This finding is comparable to those documented by Fashafsheh et al. (2015) ${ }^{(26)}$ and Sodhi et al. (2016) ${ }^{(32)}$ of $80 \%$ vaccination rates among nurses. Fashafsheh et al. $(2016)^{(33)}$ had a very high compliance to vaccination of $95.1 \%$, this they may be attributed to vigorous promotion of safety culture and climate within the hospital.

Hand hygiene is acknowledged as an essential measure to avert the spread of microorganisms from one patient to another ${ }^{(34)}$. Despite vast evidence emphasizing the significance of performing $\mathrm{HH}$, in this study the five care-related $\mathrm{HH}$ practices assessed revealed a highly varied compliance to the recommended practices. Compliance with $\mathrm{HH}$ practices was higher when the risk was perceived to be higher. This perception was demonstrated by higher percentage compliance after contact with body fluids than before touching patients. This is corroborated by Gebresilassie et al. $(2014)^{(35)}$ study on standard precautions practices among HCWs in Ethiopia, their results show that one third of nurses performed $\mathrm{HH}$ measures before procedures but a higher proportion washed their hands when there was contact with body fluids during the procedure.

The finding of a greater $\mathrm{HH}$ compliance rate after exposure with any body fluids when compared to $\mathrm{HH}$ compliance prior to patient contact suggested that participants in this study were more likely to be motivated to perform $\mathrm{HH}$ out of concerns for their own safety rather than concern for the safety of their patients.

In another study on compliance with national Palestinian IPC guidelines by 
Eljedi and Dalo (2014) ${ }^{(36)}$, they found that only minority of nurses adhered to hand washing as recommended. In addition, the overall frequency of hand washing in their study was $6.7 \%$ before patient contact and $23.7 \%$ after patient contact. Yawson et al. $(2013)^{(37)}$ study reflected the same trend with $\mathrm{HH}$ compliance rates of $9.6 \%$ to $54 \%$ among studied nurses.

Furthermore, studied nurses reported higher compliance than what was actually observed. For example, less than half of the nurses performed $\mathrm{HH}$ before contact with the patients compared to about two thirds who reported to being compliant. Eljedi and Dalo $(2014)^{(36)}$ study had similar findings showing nurses reported that they wash their hands more than they actually do; in their results, the observed compliance with $\mathrm{HH}$ practices revealed that only $45.9 \%$ of the participants performed $\mathrm{HH}$ compared with the $79.7 \%$ who had indicated otherwise in their self reports. The proportion of nurses complying with $\mathrm{HH}$ practices when in contact with different patients was at $47 \%$ implying a potentially high risk of cross infection.

For the protection from potential exposure to blood and other body fluids, nurses are expected to use different types of PPEs depending on the nature of the procedure and patient interactions ${ }^{(31)}$. The findings of present study indicate that almost all the nurses used gloves when expected during their interaction with the patients. This was higher than those reported in other studies by Gebresilassie et al. $(2014)^{(35)}$ in Ethiopia $(86.7 \%)$ and Wasswa et al. (2015) in Arua Uganda $(66 \%)^{(38)}$. On the other hand, compliance to use of gowns goggles and facemasks were very low. Gloves were the most worn protective gear probably because they are relatively affordable and available compared to other personal protective wear such as gowns ${ }^{(38)}$.

Nurses are expected to dispose all clinical waste including sharps according to local policy to prevent occupational exposures. In this study it is encouraging to note that a majority of the studied nurses were compliant with waste disposal practices; both observed and self reported scores was above $87 \%$. These findings indicate that majority of the nurses have inculcated proper waste disposal norms in their work ethics. These findings were similar with those of Gebresilassie et al. $(2014)^{(35)}$ and Hakim, Mohsen and Bakr $(2014)^{(39)}$ who reported $92.8 \%$ and $84.8 \%$ compliance among nurses respectively.

Concerning safe injection practices and sharps disposal, the results of this study showed that, after giving injection or drawing blood from patients, some nurses still recap used needles. This was similar to the findings of Wasswa et al. $(2015)^{(38)}$ where $31.9 \%$ of HCWs always recapped needles. On the contrary, Chisanga $(2017)^{(24)}$ on her study of knowledge, attitudes and practices of nurses in IPC in Zambia reported $92.8 \%$ compliance with the recommended practice. Other studies with lower prevalence of this practice (10.7\%) among nurses includes that of Esena et al. $(2013)^{(40)}$ study in Ghana. These finding shows nurses are yet to perceive the risks associated with this malpractice $^{(38)}$. Recapping of used needles is not a recommended IPC nursing practice as it predisposes nurses to sharps injuries and can be a source of infection ${ }^{(24)}$.

The current study further reveals that, almost all the nurses disposed used needles in puncture resistant containers and over three quarters of them carried safety boxes to the point of use. Ganesh et al. (2015) ${ }^{(22)}$ who investigated knowledge and practices of safe injection and disposal methods among nursing personnel; indicated that $89.5 \%$ of the nurses collected used needles and syringes in the safety box and $10.5 \%$ dispensed it with general waste.

Regarding linen management, most nurses used gloves when handling soiled linen, it was however note worthy that even fewer of them folded linen with contamination to inside. Eljedi and Dalo $(2014)^{(36)}$ in their study had comparable findings where more than two thirds of the 
nurses' were compliant with regard to linen management practices. If nurses fail to handle soiled linen with minimum agitation, using gloves and with contamination to inside; it can result to contamination of self or patient environment ${ }^{(41)}$.

Nurses are recommended to employ aseptic technique during wound dressing to avoid introducing micro organisms to susceptible body sites $^{(31)}$. However, the results in this study reveals that, while majority of the nurses believed they applied aseptic techniques during wound dressing; only slightly more than half of them were observed to be compliant. Furthermore, the results shows wide variability in application of the various aspects of sterile techniques: cleaning of procedure trolley, checking integrity of sterile packs, $\mathrm{HH}$ after the procedure and use of sterile gloves were the most complied by majority of nurses. But checking the dates of expiry of the dressing pack and maintaining asepsis throughout the wound dressing procedure had less nurses complying. Inevitably, the nurses' efforts to comply with most procedure steps of aseptic technique is undermined by non compliance in some steps hence compromising the efficacy of the technique $^{(42)}$.

This results is in support of the findings of Oluwakemi et al. $(2017)^{(43)}$ study of 'Knowledge, attitude and practice of surgical site infection prevention among post-operative nurses in a tertiary health institution in north-central Nigeria'. The study indicated that most of nurses use aseptic technique during wound dressing. But the $\mathrm{HH}$ practices in their study had fewer nurses complying compared with our study findings. Jerotich $(2016)^{(44)}$ in her study revealed that $21.4 \%$ opened sterile dressing packs aseptically and $29 \%$ checked the expiry of the packs. This finding indicates substandard compliance with aseptic techniques.

When the self reported compliance and observed compliance were compared, it showed significant difference in $\mathrm{HH}$ compliance and use of PPEs. Eljedi and
Dalo $(2014)^{(36)}$ findings are in agreement with these results. Their study reveals that in $\mathrm{HH}$ practices, only $45.9 \%$ of the participants washed their hands properly compared with the $79.7 \%$ who had indicated otherwise in their self reports. These findings imply that in hand hygiene, nurses reported to perform $\mathrm{HH}$ practices more than they actually do under observations. Also in regards to PPE use, it implies nurses' reports to use PPEs more than they actually do under observation. The observed compliance indicates a more truthful reflection of the actual practice by the nurses.

The overall nurses' compliance with IPC practices in the current study was good as majority of the nurses were compliant with recommended practices. However, compliance varied widely across different domains of IPC practice indications. This is reflected by Valim et al. $(2016)^{(45)}$ conclusion that professionals' compliance with IPC practices has remained at an irregular and worrying low level. Despite the hospital success in engendering the safety culture shift in use of gloves, waste and linen management; further organizational support in other elements of IPC is crucial to sustain high level of compliance $^{(46)}$.

\section{Conclusion}

Most of the nurses complied with the recommended IPC practices. However, there was irregular application of the IPC practices across different domains of IPC practices. Nurses self reported compliance with IPC practices was statistically significantly higher in hand hygiene practices and use of PPEs.

\section{Recommendations}

- Regular monitoring of IPC practice implementation through random infection control spot checks in the hospitals.

- The hospital should ensure adequate supply of PPEs, Alcohol based hand rubs and equipments to support effective implementation of IPC practices.

- Nurses should be encouraged to be vaccinated against Hepatitis $B$. 
Table (1): Frequency distribution of the studied nurses' according to socialdemographic data and work related characteristics

\begin{tabular}{|c|c|c|}
\hline Social-demographic data & No. $=100$ & $\%$ \\
\hline $\begin{array}{l}\text { Gender } \\
\text { Male } \\
\text { Female }\end{array}$ & $\begin{array}{l}24 \\
76\end{array}$ & $\begin{array}{l}24.0 \\
76.0\end{array}$ \\
\hline $\begin{array}{l}\text { Age (years) } \\
20-29 \\
30-39 \\
40-49 \\
50+\end{array}$ & $\begin{array}{c}13 \\
\mathbf{6 5} \\
19 \\
3\end{array}$ & $\begin{array}{l}13.0 \\
\mathbf{6 5 . 0} \\
19.0 \\
3.0\end{array}$ \\
\hline $\begin{array}{l}\text { Min. - Max. } \\
\text { Mean } \pm \text { SD. }\end{array}$ & & \\
\hline $\begin{array}{l}\text { Experience (years) } \\
<5 \text { y } \\
5-<10 \\
10-<15 \\
15+\end{array}$ & $\begin{array}{l}13 \\
\mathbf{5 0} \\
19 \\
18\end{array}$ & $\begin{array}{l}13.0 \\
\mathbf{5 0 . 0} \\
19.0 \\
18.0\end{array}$ \\
\hline $\begin{array}{l}\text { Min. - Max. } \\
\text { Mean } \pm \text { SD. }\end{array}$ & & \\
\hline $\begin{array}{l}\text { Terms of employment } \\
\text { Contract } \\
\text { Permanent and pensionable }\end{array}$ & $\begin{array}{c}0 \\
100\end{array}$ & $\begin{array}{c}0.0 \\
100.0\end{array}$ \\
\hline $\begin{array}{l}\text { Nursing education level } \\
\text { Diploma } \\
\text { Bachelors degree } \\
\text { Master's degree in nursing } \\
\end{array}$ & $\begin{array}{c}64 \\
35 \\
1 \\
\end{array}$ & $\begin{array}{c}64.0 \\
35.0 \\
1.0\end{array}$ \\
\hline $\begin{array}{l}\text { Work related characteristics } \\
\text { Hepatitis B virus vaccination } \\
\text { Yes } \\
\text { No }\end{array}$ & $\begin{array}{l}79 \\
21 \\
\end{array}$ & $\begin{array}{l}79.0 \\
21.0\end{array}$ \\
\hline $\begin{array}{l}\text { Completed vaccination }(\mathbf{n}=\mathbf{7 9}) \\
\text { Yes } \\
\text { No } \\
\text { Not sure }\end{array}$ & $\begin{array}{c}52 \\
24 \\
3\end{array}$ & $\begin{array}{c}65.8 \\
30.4 \\
3.8\end{array}$ \\
\hline $\begin{array}{l}\text { Training on infection prevention and control practices } \\
\text { (last } 6 \text { months) } \\
\text { Yes } \\
\text { No }\end{array}$ & $\begin{array}{l}24 \\
76\end{array}$ & $\begin{array}{l}24.0 \\
76.0\end{array}$ \\
\hline $\begin{array}{l}\text { Training adequacy }(\mathbf{n}=\mathbf{2 4}) \\
\text { Yes } \\
\text { No }\end{array}$ & $\begin{array}{l}12 \\
10\end{array}$ & $\begin{array}{r}54.5 . \\
45.5\end{array}$ \\
\hline $\begin{array}{l}\text { Duration of training }(\mathbf{n}=\mathbf{2 4}) \\
\text { Min. - Max. } \\
\text { Mean } \pm \text { SD. }\end{array}$ & \multicolumn{2}{|c|}{$\begin{array}{c}1.0-4.0 \\
1.46 \pm 0.83\end{array}$} \\
\hline $\begin{array}{l}\text { Sharps related injury (last } 6 \text { months) }(n=100) \\
\text { No } \\
\text { Yes }\end{array}$ & $\begin{array}{c}97 \\
\mathbf{3}\end{array}$ & $\begin{array}{c}97.0 \\
\mathbf{3 . 3}\end{array}$ \\
\hline $\begin{array}{l}\text { Reporting of sharps related injury }(\mathbf{n}=\mathbf{3}) \\
\text { Yes } \\
\text { No }\end{array}$ & $\begin{array}{l}3 \\
0\end{array}$ & $\begin{array}{c}100.0 \\
0.0\end{array}$ \\
\hline
\end{tabular}


Table (2a): Frequency distribution of studied nurses' self reported compliance with infection prevention and control practices $(n=100)$

\begin{tabular}{|c|c|c|c|c|c|c|c|}
\hline \multirow{3}{*}{\multicolumn{2}{|c|}{ Parameters regarding to IPC practices }} & \multicolumn{6}{|c|}{ Frequency of compliance } \\
\hline & & \multicolumn{2}{|c|}{ Always } & \multicolumn{2}{|c|}{ Sometimes } & \multicolumn{2}{|c|}{ Never } \\
\hline & & No. & $\%$ & No. & $\%$ & No. & $\%$ \\
\hline \multicolumn{8}{|c|}{ Hand Hygiene } \\
\hline 1. & Wash/sanitize hands before contact with any patient & 63 & 63.0 & 37 & 37.0 & 0 & 0.0 \\
\hline 2. & $\begin{array}{l}\text { Wash/ sanitize hands when in contact between different } \\
\text { patients }\end{array}$ & 47 & 47.0 & 52 & 52.0 & 1 & 1.0 \\
\hline & Wash hands after taking off gloves & 76 & 76.0 & 21 & 21.0 & 3 & 3.0 \\
\hline & $\begin{array}{l}\text { Wash hands immediately after contacting any blood, body } \\
\text { fluid, secretion, excretion or potentially contaminated } \\
\text { materials }\end{array}$ & 98 & 98.0 & 2 & 2.0 & 0 & 0.0 \\
\hline & Sanitize hands with alcohol if not visibly contaminated & 35 & 35.0 & 64 & 64.0 & 1 & 1.0 \\
\hline \multicolumn{2}{|c|}{ Non compliance } & \multicolumn{6}{|c|}{31} \\
\hline \multicolumn{2}{|c|}{ Compliance } & \multicolumn{6}{|c|}{69} \\
\hline \multirow{3}{*}{\multicolumn{2}{|c|}{\begin{tabular}{|l} 
Total \% score \\
Personal protective equipment's: gloving
\end{tabular}}} & \multicolumn{3}{|c|}{ Min -Max } & \multicolumn{3}{|c|}{ Mean \pm SD. } \\
\hline & & \multicolumn{3}{|c|}{$50.0-100.0$} & \multicolumn{3}{|c|}{$81.40 \pm 12.39$} \\
\hline & & & & & & \\
\hline 6. & $\begin{array}{l}\text { Remove gloves if visibly contaminated and perform } \\
\text { hand hygiene }\end{array}$ & 94 & 94.0 & 6 & 6.0 & 0 & 0.0 \\
\hline 7. & Glove when drawing blood samples & 91 & 91.0 & 9 & 9.0 & 0 & 0.0 \\
\hline 8. & Glove when disposing stool and urine & 97 & 97.0 & 2 & 2.0 & 1 & 1.0 \\
\hline 9. & Glove when handling impaired patient skin & 96 & 96.0 & 3 & 3.0 & 1 & 1.0 \\
\hline 10. & Glove when handling patients' mucosa & 95 & 95.0 & 4 & 4.0 & 1 & 1.0 \\
\hline 11. & Glove when handling saliva or sputum culture & 98 & 98.0 & 0 & 0.0 & 2 & 2.0 \\
\hline 12. & Glove when administering parenteral medications & 84 & 84.0 & 16 & 16.0 & 0 & 0.0 \\
\hline 13. & Glove when dressing wounds & 100 & 100.0 & 0 & 0.0 & 0 & 0.0 \\
\hline 14. & Glove when cleaning blood traces & 100 & 100.0 & 0 & 0.0 & 0 & 0.0 \\
\hline 15. & Glove when performing venipuncture & 89 & 89.0 & 11 & 11.0 & 0 & 0.0 \\
\hline \multicolumn{2}{|c|}{ Non compliance } & \multicolumn{6}{|c|}{1} \\
\hline \multicolumn{2}{|c|}{ Compliance } & \multicolumn{6}{|c|}{99} \\
\hline \multicolumn{2}{|c|}{ Total \% score } & \multicolumn{3}{|c|}{$\begin{array}{r}\text { Min. - Max. } \\
70.0-100.0\end{array}$} & \multicolumn{3}{|c|}{$\begin{array}{l}\text { Mean } \pm \text { SD } \\
96.85 \pm 5.25\end{array}$} \\
\hline
\end{tabular}


Table (2b): Frequency distribution of studied nurses according to their compliance with IPC practices PPE (masks, goggles and gown), linen and waste management domains $(\mathbf{n}=\mathbf{1 0 0})$

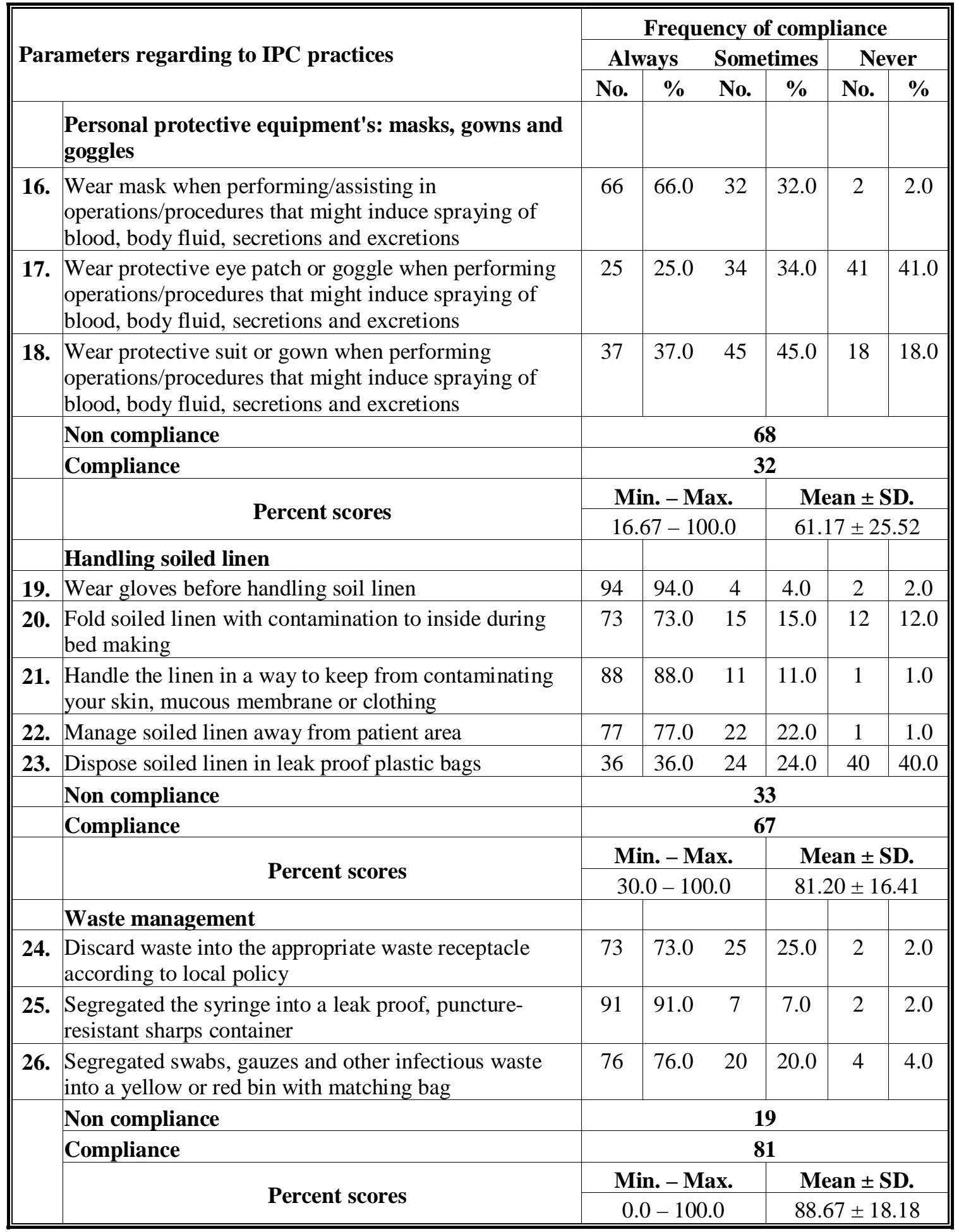


Table (2c): Frequency distribution of studied nurses according to their compliance with IPC practices (safe injection practices and aseptic technique domains) (no=100)

\begin{tabular}{|c|c|c|c|c|c|c|c|}
\hline & \multirow{3}{*}{ Parameters regarding to IPC practices } & \multicolumn{6}{|c|}{ Frequency of compliance } \\
\hline & & \multicolumn{2}{|c|}{ Always } & \multicolumn{2}{|c|}{ Sometimes } & \multicolumn{2}{|c|}{ Never } \\
\hline & & No. & $\%$ & No. & $\%$ & No. & $\%$ \\
\hline & Safe injection practices & & & & & & \\
\hline 27. & $\begin{array}{l}\text { Use the one-hand syringe recapping method/ don't } \\
\text { recap used syringe }\end{array}$ & 68 & 68.0 & 19 & 19.0 & 13 & 13.0 \\
\hline 28. & $\begin{array}{l}\text { Dispose needles and blades in containers that are } \\
\text { specific for that purpose }\end{array}$ & 95 & 95.0 & 4 & 4.0 & 1 & 1.0 \\
\hline 29. & $\begin{array}{l}\text { Carry safety box for point of use disposal of used } \\
\text { sharps }\end{array}$ & 78 & 78.0 & 20 & 20.0 & 2 & 2.0 \\
\hline 30. & $\begin{array}{l}\text { In case of workplace accidents with potentially- } \\
\text { contaminated sharp materials, immediately squeezes } \\
\text { the affected part, disinfects it, and dresses the wound }\end{array}$ & 66 & 66.0 & 21 & 21.0 & 13 & 13.0 \\
\hline 31. & $\begin{array}{l}\text { Report all risk-exposure incidents, even when the } \\
\text { incident is of high- or low-risk exposure }\end{array}$ & 65 & 65.0 & 32 & 32.0 & 3 & 3.0 \\
\hline \multirow[t]{6}{*}{32.} & Close and seal the sharps box when $2 / 3$ full & 37 & 37.0 & 42 & 42.0 & 21 & 21.0 \\
\hline & Non compliance & \multicolumn{6}{|c|}{30} \\
\hline & Compliance & \multicolumn{6}{|c|}{70} \\
\hline & \multirow{2}{*}{ Percent scores } & \multicolumn{3}{|c|}{ Min. - Max. } & \multicolumn{3}{|c|}{ Mean \pm SD. } \\
\hline & & \multicolumn{3}{|c|}{$41.67-100.0$} & \multicolumn{3}{|c|}{$79.67 \pm 15.23$} \\
\hline & Surgical wound dressing aseptic technique & & & & & & \\
\hline 33. & $\begin{array}{l}\text { Clean the trolley/tray/surface with detergent and } \\
\text { water or detergent wipes before wound dressing }\end{array}$ & 91 & 91.0 & 9 & 9.0 & 0 & 0.0 \\
\hline 34. & $\begin{array}{l}\text { Check the integrity of sterile packs prior to use for } \\
\text { any procedure in the ward }\end{array}$ & 85 & 85.0 & 12 & 12.0 & 3 & 3.0 \\
\hline 35. & Check the expiry date of sterile packs prior to use & 61 & 61.0 & 32 & 32.0 & 7 & 7.0 \\
\hline 36. & $\begin{array}{l}\text { Remove sterile packs from their outer packaging } \\
\text { using a non-touch technique }\end{array}$ & 76 & 76.0 & 23 & 23.0 & 1 & 1.0 \\
\hline 37. & $\begin{array}{l}\text { Open the sterile packs using only the corners of the } \\
\text { wrapping, taking care not to touch any of the sterile } \\
\text { contents }\end{array}$ & 78 & 78.0 & 21 & 21.0 & 1 & 1.0 \\
\hline 38. & $\begin{array}{l}\text { Arrange the items on the sterile field using sterile } \\
\text { gloves }\end{array}$ & 66 & 66.0 & 31 & 31.0 & 3 & 3.0 \\
\hline 39. & $\begin{array}{l}\text { Use non sterile gloves to remove old wound } \\
\text { dressings }\end{array}$ & 72 & 72.0 & 25 & 25.0 & 3 & 3.0 \\
\hline 40. & Perform hand hygiene after dressing removal & 75 & 75.0 & 23 & 23.0 & 2 & 2.0 \\
\hline 41. & Maintain asepsis throughout the wound dressing & 82 & 82.0 & 18 & 18.0 & 0 & 0.0 \\
\hline 42. & Dress a wound site with sterile dressing & 88 & 88.0 & 12 & 12.0 & 0 & 0.0 \\
\hline \multirow[t]{6}{*}{43.} & $\begin{array}{l}\text { Ensure no contamination of the outer surface of } \\
\text { sterile gloves if worn }\end{array}$ & 86 & 86.0 & 14 & 14.0 & 0 & 0.0 \\
\hline & Non compliance & \multicolumn{6}{|c|}{14} \\
\hline & Compliance & \multicolumn{6}{|c|}{86} \\
\hline & \multirow{2}{*}{ Percent scores } & \multirow{2}{*}{\multicolumn{3}{|c|}{$\frac{1}{\text { Min. - Max. }}$}} & \multicolumn{3}{|c|}{ Mean \pm SD. } \\
\hline & & & & & \multicolumn{3}{|c|}{$88.67 \pm 18.18$} \\
\hline & Overall total compliance \% score & \multicolumn{3}{|c|}{$\frac{0.0-100.0}{63.95-\mathbf{1 0 0 . 0}}$} & & $58 \pm 8$ & \\
\hline
\end{tabular}


Table (3a): Frequency distribution of the studied nurses according to the observed compliance with IPC practices (hand hygiene, PPE and injection safety domains) (no=100)

\begin{tabular}{|c|c|c|c|c|c|c|}
\hline \multirow{3}{*}{ Compliance activity } & \multicolumn{6}{|c|}{ Level of compliance } \\
\hline & \multicolumn{2}{|c|}{ Compliant } & \multicolumn{2}{|c|}{$\begin{array}{c}\text { Non- } \\
\text { compliant }\end{array}$} & \multicolumn{2}{|c|}{$\begin{array}{c}\text { Not } \\
\text { applicable }\end{array}$} \\
\hline & No. & $\%$ & No. & $\%$ & No. & $\%$ \\
\hline \multicolumn{7}{|l|}{ Hand hygiene } \\
\hline 1. Washes/sanitizes hands before touching a patient & 49 & 49.0 & 51 & 51.0 & 0 & 0.0 \\
\hline $\begin{array}{l}\text { 2. Washes/sanitizes hands when in contact between } \\
\text { different patients }\end{array}$ & 35 & 35.0 & 65 & 65.0 & 0 & 0.0 \\
\hline 3. Washes/sanitizes hands after taking off gloves. & 89 & 89.0 & 11 & 11.0 & 0 & 0.0 \\
\hline Washes hands immediately after contacting any & 96 & 96.0 & 4 & 4.0 & 0 & 0.0 \\
\hline $\begin{array}{l}\text { 4. blood, body fluid, secretion, excretion or potentially } \\
\text { contaminated materials }\end{array}$ & & & & & & \\
\hline $\begin{array}{l}\text { 5. } \\
\begin{array}{l}\text { Performs hand hygiene after dressing/device } \\
\text { removal }\end{array}\end{array}$ & 89 & 89.0 & 6 & 6.0 & 5 & 5.0 \\
\hline Subtotal \% compliance & 55 & 55.0 & 45 & 45.0 & $\mathbf{0}$ & 0.0 \\
\hline \multicolumn{7}{|l|}{ Personal protective equipment's } \\
\hline 6. Wears gloves when drawing blood samples. & 40 & 40.0 & 5 & 5.0 & 55 & 55.0 \\
\hline 7. Wears gloves when disposing stool and urine. & 83 & 83.0 & 0 & 0.0 & 17 & 17.0 \\
\hline 8. Wears gloves when handling impaired patient skin. & 95 & 95.0 & 0 & 0.0 & 5 & 5.0 \\
\hline 9. Wears gloves when handling patients' mucosa. & 79 & 79.0 & 0 & 0.0 & 21 & 21.0 \\
\hline 10. Wears gloves when handling saliva/sputum culture. & 53 & 53.0 & 0 & 0.0 & 47 & 47.0 \\
\hline 11. Wears gloves when giving parenteral injection & 88 & 88.0 & 2 & 2.0 & 10 & 10.0 \\
\hline 12. Wears gloves when dressing wounds. & 88 & 88.0 & 2 & 2.0 & 10 & 10.0 \\
\hline 13. Wears gloves when cleaning blood trace. & 96 & 96.0 & 1 & 1.0 & 3 & 3.0 \\
\hline 14. Wears gloves when comes in contact with blood. & 95 & 95.0 & 1 & 1.0 & 4 & 4.0 \\
\hline 15. Wears gloves when performing venipuncture & 80 & 80.0 & 3 & 3.0 & 17 & 17.0 \\
\hline Wears mask when performing procedures that & 77 & 77.0 & 17 & 17.0 & 6 & 6.0 \\
\hline $\begin{array}{l}\text { 16. might induce spraying of blood, body fluid, } \\
\text { secretions and excretions. }\end{array}$ & & & & & & \\
\hline $\begin{array}{l}\text { Wears protective eye patch or goggle when } \\
\text { performing operations/procedures that might induce }\end{array}$ & 14 & 14.0 & 63 & 63.0 & 23 & 23.0 \\
\hline 17. $\begin{array}{l}\text { performing operations/procedures that might induce } \\
\text { spraying of blood, body fluid, secretions and } \\
\text { excretions. }\end{array}$ & & & & & & \\
\hline Wears protective suit or gown when performing & 38 & 38.0 & 45 & 45.0 & 17 & 17.0 \\
\hline $\begin{array}{l}\text { 18. operations/procedures that might induce spraying of } \\
\text { blood, body fluid, secretions and excretions. }\end{array}$ & & & & & & \\
\hline Subtotal \% compliance & 92 & 92.0 & 8 & 8.0 & $\mathbf{0}$ & $\mathbf{0 . 0}$ \\
\hline \multicolumn{7}{|l|}{ Sharps disposal } \\
\hline 19. Do not recap syringe after using. & 78 & 78.0 & 21 & 21.0 & 1 & 1.0 \\
\hline $\begin{array}{l}\text { 20. Disposes needles and blades in containers that are } \\
\text { specific for that purpose }\end{array}$ & 88 & 88.0 & 4 & 4.0 & 8 & 8.0 \\
\hline $\begin{array}{l}\text { 21. In case of workplace accidents with potentially- } \\
\text { contaminated sharp materials, immediately } \\
\text { squeezes the } \\
\text { affected part, disinfects it, and dresses the wound }\end{array}$ & 0 & 0 & 0 & 0 & 100 & 100 \\
\hline \begin{tabular}{l|l} 
22. & Report all risk-exposure incidents
\end{tabular} & 0 & 0 & 0 & 0 & 100 & 100 \\
\hline 23. Seal the sharps box when $3 / 4$ full & 39 & 39.0 & 49 & 49.0 & 12 & 12.0 \\
\hline Subtotal \% compliance & 61 & 61.0 & 39 & 39.0 & $\mathbf{0}$ & $\mathbf{0 . 0}$ \\
\hline Overall compliance & & & & & & \\
\hline
\end{tabular}


Table (3b): Frequency distribution of the studied cases according to the observed compliance with IPC practices (linen management, waste disposal and aseptic technique $)(n=100)$

\begin{tabular}{|c|c|c|c|c|c|c|}
\hline \multirow{3}{*}{ Compliance activity } & \multicolumn{6}{|c|}{ Compliance } \\
\hline & \multicolumn{2}{|c|}{ Compliant } & \multicolumn{2}{|c|}{$\begin{array}{c}\text { Non- } \\
\text { compliant }\end{array}$} & \multicolumn{2}{|c|}{$\begin{array}{c}\text { Not } \\
\text { applicable }\end{array}$} \\
\hline & No. & $\%$ & No. & $\%$ & No. & $\%$ \\
\hline \multicolumn{7}{|l|}{ Linen management } \\
\hline 1. Wears gloves before handling soil linen? & 94 & 94.0 & 6 & 6.0 & 0 & 0.0 \\
\hline $\begin{array}{l}\text { 2. Folds soiled linen with contamination to inside } \\
\text { during bed making }\end{array}$ & 69 & 69.0 & 30 & 30.0 & 1 & 1.0 \\
\hline Handles the linen in a way to keep it from & 73 & 73.0 & 25 & 25.0 & 2 & 2.0 \\
\hline $\begin{array}{l}\text { 3. contaminating the skin, mucous membrane or } \\
\text { clothing }\end{array}$ & & & & & & \\
\hline 4. Managed soiled linen away from patient area. & 85 & 85.0 & 14 & 14.0 & 1 & 1.0 \\
\hline Subtotal \% compliance & 74 & $\mathbf{7 4 . 0}$ & 26 & 26.0 & $\mathbf{0}$ & $\mathbf{0 . 0}$ \\
\hline \multicolumn{7}{|l|}{ Waste disposal } \\
\hline $\begin{array}{l}\text { 5. Discarded waste into the appropriate waste stream } \\
\text { according to local policy? }\end{array}$ & 80 & 80.0 & 20 & 20.0 & 0 & 0.0 \\
\hline $\begin{array}{l}\text { 6. Segregated the syringe into a leak proof, puncture- } \\
\text { resistant sharps container }\end{array}$ & 95 & 95.0 & 2 & 2.0 & 3 & 3.0 \\
\hline $\begin{array}{l}\text { 7. Segregated swabs, gauzes and other infectious } \\
\text { waste into a yellow or red bin with matching bag }\end{array}$ & 80 & 80.0 & 20 & 20.0 & 0 & 0.0 \\
\hline $\begin{array}{l}\text { 8. Performed hand hygiene immediately following } \\
\text { removal of personal protective equipment? }\end{array}$ & 92 & 92.0 & 8 & 8.0 & 0 & 0.0 \\
\hline Subtotal \% compliance & 89 & 89.0 & 11 & 11.0 & $\mathbf{0}$ & 0.0 \\
\hline \multicolumn{7}{|l|}{ Use of aseptic techniques } \\
\hline $\begin{array}{l}\text { 9. Clean the trolley/tray/surface with detergent and } \\
\text { water or detergent wipes and then dried? }\end{array}$ & 85 & 85.0 & 14 & 14.0 & 1 & 1.0 \\
\hline $\begin{array}{l}\text { 10. Check the integrity of sterile packs prior to use for } \\
\text { any procedure in the ward? }\end{array}$ & 65 & 65.0 & 25 & 25.0 & 10 & 10.0 \\
\hline $\begin{array}{l}\text { 11. Check the expiry date of sterile packs checked } \\
\text { prior to use? }\end{array}$ & 46 & 46.0 & 44 & 44.0 & 10 & 10.0 \\
\hline $\begin{array}{l}\text { 12. Are sterile packs removed from their outer } \\
\text { packaging using a non touch technique? }\end{array}$ & 56 & 56.0 & 36 & 36.0 & 8 & 8.0 \\
\hline $\begin{array}{l}\text { 13. Are the sterile packs opened using only the corners } \\
\text { of the package? }\end{array}$ & 65 & 65.0 & 28 & 28.0 & 7 & 7.0 \\
\hline $\begin{array}{l}\text { 14. Are items arranged on the sterile field using sterile } \\
\text { gloves? }\end{array}$ & 63 & 63.0 & 32 & 32.0 & 5 & 5.0 \\
\hline $\begin{array}{l}\text { 15. Are non sterile gloves worn to remove the } \\
\text { dressing/device? }\end{array}$ & 93 & 93.0 & 5 & 5.0 & 2 & 2.0 \\
\hline $\begin{array}{l}\text { 16. Is hand hygiene performed after dressing/device } \\
\text { removal }\end{array}$ & 95 & 95.0 & 0 & 0.0 & 0 & 0.0 \\
\hline $\begin{array}{l}\text { 17. If sterile gloves are worn, are they put on in a way } \\
\text { that prevents contamination of the outer surface? }\end{array}$ & 76 & 76.0 & 22 & 22.0 & 2 & 2.0 \\
\hline 18. Is asepsis maintained through the procedure? & 52 & 52.0 & 44 & 44.0 & 4 & 4.0 \\
\hline 19. Is a sterile dressing placed over the wound/site? & 90 & 90.0 & 6 & 6.0 & 4 & 4.0 \\
\hline Subtotal \% compliance & 55 & 55.0 & 45 & 45.0 & $\mathbf{0}$ & $\mathbf{0 . 0}$ \\
\hline
\end{tabular}


Table (4): Relations between the studied nurses' self reported IPC practice compliance with their social demographic and work related characteristics $($ no=100)

\begin{tabular}{|c|c|c|c|c|c|c|c|}
\hline \multirow{3}{*}{\multicolumn{2}{|c|}{$\begin{array}{l}\text { Social-demographic and work } \\
\text { related characteristics }\end{array}$}} & \multicolumn{4}{|c|}{ Overall compliance } & \multirow{3}{*}{$\chi^{2}$} & \multirow{3}{*}{${ }^{\mathrm{MC}} \mathbf{p}$} \\
\hline & & \multicolumn{2}{|c|}{$\begin{array}{c}\text { Noncompliance } \\
(\mathbf{n}=11)\end{array}$} & \multicolumn{2}{|c|}{$\begin{array}{c}\text { compliance } \\
(\mathbf{n}=89)\end{array}$} & & \\
\hline & & No. & $\%$ & No. & $\%$ & & \\
\hline \multicolumn{2}{|l|}{ Age } & 1 & 9.1 & 12 & 13.5 & \multirow{4}{*}{0.352} & \multirow{4}{*}{1.000} \\
\hline \multicolumn{2}{|l|}{$30-39$} & 8 & 72.7 & 57 & 64.0 & & \\
\hline \multicolumn{2}{|l|}{$40-49$} & 2 & 18.2 & 17 & 19.1 & & \\
\hline & 0 & 0.0 & 3 & 3.4 & & \\
\hline \multicolumn{8}{|l|}{ Education level } \\
\hline \multicolumn{2}{|l|}{ Diploma } & 6 & 54.5 & 58 & 65.2 & \multirow{3}{*}{1.385} & \multirow{3}{*}{0.566} \\
\hline Degree & & 5 & 45.5 & 30 & 33.7 & & \\
\hline Masters & & 0 & 0.0 & 1 & 1.1 & & \\
\hline \multicolumn{8}{|l|}{\begin{tabular}{|l} 
Years of experience \\
\end{tabular}} \\
\hline$<5 \mathrm{y}$ & & 0 & 0.0 & 13 & 14.6 & \multirow{4}{*}{2.653} & \multirow{4}{*}{0.455} \\
\hline $5-<10$ & & 8 & 72.7 & 42 & 47.2 & & \\
\hline $10-<15$ & & 2 & 18.2 & 17 & 19.1 & & \\
\hline $15+$ & & 1 & 9.1 & 17 & 19.1 & & \\
\hline \multirow{2}{*}{\begin{tabular}{|l} 
Training on infection \\
prevention and control \\
practices $(>6$ months $)$
\end{tabular}} & Yes & 1 & 9.1 & 23 & 25.8 & \multirow{2}{*}{1.506} & \multirow{2}{*}{$\begin{array}{r}\mathrm{FE}_{\mathrm{p}}= \\
0.289\end{array}$} \\
\hline & No & 10 & 90.9 & 66 & 74.2 & & \\
\hline \multirow{2}{*}{$\begin{array}{l}\text { In the last six months, } \\
\text { have you had any } \\
\text { sharps related injury? }\end{array}$} & Yes & 0 & 0.0 & 3 & 4.1 & & \\
\hline & No & 26 & 100.0 & 71 & 95.9 & & \\
\hline
\end{tabular}

$\chi^{2}, p: \chi^{2}$ and $p$ values for Chi square test

${ }_{M C} p$ : $p$ value for Monte Carlo for Chi square test

${ }^{F E}$ p: $p$ value for Fisher Exact for Chi square test

Table (5): Comparison between the nurses' self reported and the observed compliance scores in three selected IPC domains $(n=100)$

\begin{tabular}{|c|c|c|c|c|}
\hline$\%$ score & $\begin{array}{c}\text { Observed } \\
\text { compliance }\end{array}$ & $\begin{array}{c}\text { Self reported } \\
\text { Compliance }\end{array}$ & $\mathbf{t}$ & $\mathbf{p}$ \\
\hline $\begin{array}{l}\text { Hand hygiene } \\
\text { Min. - Max. } \\
\text { Mean } \pm \text { SD. }\end{array}$ & $\begin{array}{c}20.0-100.0 \\
72.25 \pm 22.57\end{array}$ & $\begin{array}{c}50.0-100.0 \\
81.40 \pm 12.39\end{array}$ & $3.682^{*}$ & $<0.001^{*}$ \\
\hline $\begin{array}{l}\text { Personal protective equipment's } \\
\text { Min. - Max. } \\
\text { Mean } \pm \text { SD. }\end{array}$ & $\begin{array}{l}55.56-100.0 \\
87.52 \pm 10.22 \\
\end{array}$ & $\begin{array}{l}16.67-100.0 \\
61.17 \pm 25.52 \\
\end{array}$ & $9.246^{*}$ & $<0.001^{*}$ \\
\hline $\begin{array}{l}\text { Waste disposal } \\
\text { Min. - Max. } \\
\text { Mean } \pm \text { SD. }\end{array}$ & $\begin{array}{c}25.0-100.0 \\
87.42 \pm 19.04\end{array}$ & $\begin{array}{c}0.0-100.0 \\
88.67 \pm 18.18\end{array}$ & 0.451 & 0.653 \\
\hline $\begin{array}{l}\text { Overall } \\
\text { Min. - Max. } \\
\text { Mean } \pm \text { SD. }\end{array}$ & $\begin{array}{l}47.50-100.0 \\
79.99 \pm 11.88 \\
\end{array}$ & $\begin{array}{c}63.95-100.0 \\
85.58 \pm 8.35 \\
\end{array}$ & $3.997^{*}$ & $<0.001^{*}$ \\
\hline
\end{tabular}

$t$, $p$ : $t$ and $p$ values for Paired t-test for comparing between observed and self reported compliance

*: Statistically significant at $p \leq 0.05$ 


\section{References}

1. Atalla HR, Aboalizm SE, Shaban HA. Effect of Nursing Guidelines Compliance To Infection Control Among Nursing Student. IOSR J Nurs Heal Sci. 2016;5(1):23-34.

2. Moi Teaching and Referral Hospital. Guidelines for the Prevention and Control of Infection in Healthcare. Eldoret, Kenya: Sanaa; 2014. p. 448.

3. Chakravarthy M, Myatra SN, Rosenthal VD, Udwadia FE, Gokul BN, Divatia J V., et al. The impact of the International Nosocomial Infection Control Consortium (INICC) multicenter, multidimensional hand hygiene approach in two cities of India. J Infect Public Health. 2015; 8(2):177-86.

4. Bagheri Nejad S, Allegranzi B, Syed SB, Ellis B, Pittet D, You E, et al. World Health Organization: Report on the Burden of Endemic Health Care-Associated Infection Worldwide. Am J Infect Control. 2014; 44(2):1-9.

5. World health Organization. Health careassociated infections Fact sheet. World Heal Organ. 2015; 4. Available at: http://www.who.int/gpsc/country_work/gpsc_cci sc fact sheet en.pdf.

6. Storr J, Twyman A, Zingg W, Damani N, Kilpatrick C, Reilly J, et al. Core Components for Effective Infection Prevention and Control Programmes: New WHO Evidence-Based Recommendations. Antimicrob Resist Infect Control. 2017 Dec 10; 6(1):6.

7. Mbim E, Mboto C, Agbo B. A Review of Nosocomial Infections in Sub-Saharan Africa. $\mathrm{Br}$ Microbiol Res J. 2016 Jan 10; 15(1):1-11.

8. World Health Organization. Consultative meeting on antimicrobial resistance for countries in the Eastern Mediterranean Region: from policies to action. 2013.

9. Nejad SB, Allegranzi B, Syed SB, Ellis B, Pittet D, Bagheri Nejad S, et al. Health-care-associated infection in Africa: a systematic review. Bull World Health Organ. 2011 Oct 1; 89(10):75765.

10. Ministry of Health. National Infection Prevention and Control Guidelines for Health Care Services in Kenya. 2nd. Nairobi, Kenya: Government of Kenya; 2016.

11. Aiken AM, Wanyoro AK, Mwangi J, Mulingwa $\mathrm{P}$, Wanjohi $\mathrm{J}$, Njoroge $\mathrm{J}$, et al. Evaluation of surveillance for Surgical Site Infections in Thika Hospital, Kenya. J Hosp Infect. 2013; 83(2):1405.

12. Siegel JD, Rhinehart E, Jackson M, Chiarello L. 2007 Guideline for Isolation Precautions: Preventing Transmission of Infectious Agents in Health Care Settings. Am J Infect Control. 2007; 35(10 SUPPL. 2).

13. Bedoya G, Dolinger A, Rogo K, Mwaura N, Wafula F, Coarasa J, et al. Observations of infection prevention and control practices in primary health care, Kenya. Bull World Health Organ. 2017; 95(7):503-16.

14. Moro ML, Luisa M. Health Care-associated Infections. Surg Infect (Larchmt). 2006 Jul; 7 Suppl 2(SUPPL. 2):S21-3.

15. Zhou Y, Zhang D, Chen Y, Zhou S, Pan S, Huang Y, et al. Healthcare-associated Infections and Shanghai Clinicians: A multicenter CrossSectional Study. PLoS One. 2014; 9(8).

16. Gichuhi AW, Kamau SM, Nyangena E, Otieno Ayayo Ngalo Z. Health Care Workers Adherence to Infection Prevention Practices and Control Measures: A Case of a Level Four District Hospital in Kenya. Am J Nurs Sci. 2015; 4(2):39.

17. Zachariah P, Furuya EY, Edwards J, Dick A, Liu $\mathrm{H}$, Herzig CTA, et al. Compliance with prevention practices and their association with central line-associated bloodstream infections in neonatal intensive care units. Am $\mathrm{J}$ Infect Control. 2014; 42(8):847-51.

18. Prathibha D'Souza.V and Umarani.J. Awareness of Students on Prevention of Nosocomial Infection in Pediatric Wards. Int $\mathbf{J}$ Pharm Biol Sci. 2014; 4(2):66-71.

19. Kim KM, Oh H. Clinical Experiences as Related to Standard Precautions Compliance among Nursing Students: A Focus Group Interview Based on the Theory of Planned Behavior. Asian Nurs Res (Korean Soc Nurs Sci). 2015; 9(2):109-14. 
20. Leaper DJ, Edmiston CE. World Health Organization: global guidelines for the prevention of surgical site infection. J Hosp Infect. 2017; 95(2):135-6.

21. Anderson DJ, Podgorny K, Berríos-Torres SI, Bratzler DW, Dellinger EP, Greene L, et al. Strategies to Prevent Surgical Site Infections in Acute Care Hospitals: 2014 Update. Infect Control Hosp Epidemiol. 2014; 35(6):605-27.

22. Ganesh S, Raghunath N, Balaji S. Assessment of safe injection practices and disposal methods among nursing personnel at health care centres of Hoskote - Rural Bengaluru, India. J Indian Assoc Public Heal Dent. 2015; 13(4):475.

23. Kamunge EW. Exploring Knowledge, Attitudes and Practices of Registered Nurses Regarding the Spread of Nosocomial Infections. Vol. 1865, Seton Hall University Dissertations and Theses (ETDs). 2013.

24. Chisanga CP. Knowledge, Attitudes and Practices of Nurses in Infection Prevention and Control Within a Tertiary Hospital in Zambia. 2017; (March).

25. Martha Rogers. Ministry of Health: Kenya Nursing Workforce Report The Status of Nursing in Kenya. 2012 p. 1-59.

26. Fashafsheh Ahmad Ayed I, Eqtait Lubna Harazneh F. Knowledge and Practice of Nursing Staff towards Infection Control Measures in the Palestinian Hospitals. J Educ Pract. 2015; 6(4):79-91.

27. Moyo GM. Factors influencing compliance with infection prevention standard precautions among nurses working at Mbagathi District Hospital, Nairobi, Kenya. 2013; 74.

28. Shurafi SOM. Nurses' compliance to infection control precautions: management of patient care equipment at the medical and surgical departments. 2015.

29. Tirivanhu C, Ancia M, Petronella S. Barriers to infection prevention and control ( IPC) practice among nurses at Bindura Provincial Hospital , Zimbabwe. 2014; 3(1):69-73.

30. Adly RM, Amin FM, Ahamed M, El A. Improving Nurses $\hat{a} €^{\mathrm{TM}}$ Compliance with Standard Precautions of Infection Control in Pediatric Critical Care Units. 2014; 1-9.
31. Siegel JD, Rhinehart E, Jackson M, Chiarello L, the Healthcare Infection Control Practices Advisory Committee. 2007 Guideline for Isolation Precautions: Preventing Transmission of Infectious Agents in Healthcare Settings. Cdc. 2007 Dec; 35(May 2016):1-203. Available at: https://www.cdc.gov/infectioncontrol/guidelines/ isolation/index.html\%0AMumps

32. Sodhi J, Satpathy S, Sharma DK, Lodha R, Kapil A, Wadhwa $\mathrm{N}$, et al. Healthcare associated infections in paediatric intensive care unit of a tertiary care hospital in India: Hospital stay \& extra costs. Indian J Med Res. 2016; 9(4):399402.

33. Fashafsheh I, Ayed A, Koni M, Hussein S, Thultheen I. Midwives and Nurses Compliance with Standard Precautions in Palestinian Hospitals. 2016; (April): 294-302.

34. Pittet D, Allegranzi B, Storr J. The WHO Clean Care is Safer Care programme: Field-testing to enhance sustainability and spread of hand hygiene improvements. J Infect Public Health. 2008; 1(1):4-10.

35. Gebresilassie A, Kumei A, Yemane D. Standard Precautions Practice among Health Care Workers in Public Health Facilities of Mekelle Special Zone, Northern Ethiopia. J Community Med Health Educ. 2014; 4(3):1000286.

36. Eljedi A, Dalo S. Compliance with the national palestinian infection prevention and control protocol at governmental paediatric hospitals in Gaza governorates. Sultan Qaboos Univ Med J. 2014 Aug; 14(3):375-81.

37. Yawson AE, Hesse AAJ, Hesse AAJ. Hand hygiene practices and resources in a teaching hospital in Ghana. 2013 Apr 17; 7:338-47.

38. Wasswa P, Nalwadda CK, Buregyeya E, Gitta $\mathrm{SN}$, Anguzu P, Nuwaha F. Implementation of infection control in health facilities in Arua district, Uganda: a cross-sectional study. BMC Infect Dis. 2015; 15(1):268.

39. Hakim S, Mohsen A, Bakr I. Knowledge, attitudes and practices of health-care personnel towards waste disposal management at Ain Shams University Hospitals, Cairo. East Mediterr Heal J. 2014; 20(5):347-54. 
40. Esena RK, Aziz A, Dotse-Gborgbortsi W. Assessment of Injection Safety Practices in Health Facilities In Bongo And Talensi Districts In The Upper East Region Of Ghana: Part 2Waste Disposal System. 2013; 2(11).

41. Dalziel C. Standard Infection Control Precautions Literature Review: Safe management of linen in the hospital setting. 2012; (January):1-32.

42. Delves-Yates C. Essentials of nursing practice. Eight edit. Stockert Hall: Potter Perry; 2015. 712 p.

43. Oluwakemi AK, Salisu A, Sanusi RA, Hanson VF, Adelani T. Knowledge, attitude and practice of surgical site infection prevention among postoperative nurses in a tertiary health institution in north-central Nigeria. Int $\mathrm{J}$ Nurs Midwifery. 2017; 9(6):65-9.

44. Jerotich CJ, Odhiambo AE, Mwaura J. Assessment of Aseptic Technique Among Nurses in Management of Burns Patients at Kenyatta National Hospital. 2016.

45. Valim D, Morais M De, Marziale RB, Palucci H. Instruments and impacting factors on standard precautions knowledge among health workers. 2016; 41:305-21.

46. Benson S, Powers J. Your role in infection prevention practice. Nurs made Incred Easy. 2011; 9(3):36-41. 